\title{
La virgen de los sicarios o la descomposición del poder
}

\author{
José Manuel Torres Torres*
}

¿Que mis críticas son

superficiales, triviales?

La virgen de los sicarios

Resumen:

El presente artículo sobre La virgen de los sicarios de Fernando Vallejo, en primer término, revisa el estado de los principales estudios acerca de la novela en relación con las diversas perspectivas que postulan sus respectivos investigadores. En segundo término, a partir de las ideas de poder de Michael Foucault, entendidas no como una teoría sino como un conjunto de análisis que permiten entender el funcionamiento del poder, nos proponemos revisar y comprender el discurso de la novela como un ejercicio crítico: por una parte, desde un trasfondo histórico, encuentra sus raíces en la formación del Estado-nación a través de un fuerte dominio de la oligarquía, y, por otra, muestra un lenguaje que mezcla el español estándar del narrador-protagonista y la jerga denominada "parlache" de las clases desposeídas de Medellín. La descomposición del poder se representa a través de dos instituciones de Colombia: el Estado y la Iglesia, a las cuales se agrega en época reciente el narcotráfico, provocando una espiral de violencia que hasta hoy no encuentra soluciones sustentables en el tiempo. En ese sentido, es posible entender la vigencia de la temática expuesta en la novela, vigencia que se valida con los sucesos que actualmente afectan a Colombia.

* Pontificia Universidad Católica de Valparaíso. 
Palabras clave:

Foucault, Historia, Estado, Iglesia, narcotráfico, violencia, Fernando Vallejo, Virgen de los sicarios, Colombia.

La novela La virgen de los sicarios ${ }^{1}$ de Fernando Vallejo se ha convertido desde su fecha de publicación (1994) en un libro emblemático del proceso de crisis que vive Colombia, ayudado por la recepción de su traducción en Francia y por la valorización de la película homónima, a lo cual se debe agregar el éxito obtenido por la novela de Jorge Franco Rosario Tijeras (1999), que también es llevada al cine. Ambos textos provocan una mirada diferente acerca del tráfico de drogas con respecto a su representación artística. En ese sentido es significativo lo que señala von der Walde: "El fenómeno es interesante, no sólo porque permite percibir el efecto de las fuerzas del mercado en la creación de modas y tendencias. Un problema social y político, como es el sicariato, ha devenido en temática" ("La novela de sicarios" 28). Aunado a esto, la novela de sicarios se ha convertido "en nueva fórmula del éxito como superación del realismo mágico"; a nuestro juicio abre paso a lo que se podría denominar "realismo cruento" si consideramos el conjunto de novelas y también de películas que aborda la temática del narcotráfico y que en ellas la presencia de la sangre y de la muerte establecen su impronta de manera relevante con respecto a una nueva forma de manifestación de la violencia en la literatura latinoamericana.

De su valor literario dan cuenta diversos investigadores que han abordado el texto a través de artículos y tesis doctorales. Entre los estudios de mayor importancia que aporta la crítica se encuentra el de María Fernanda Lander, que apunta, a partir de la picaresca, a la constitución de un género denominado "sicaresca", cuyos personajes, víctimas y victimarios, representan a través de la violencia las dos realidades que configuran la ciudad. Erna von der Walde también se suma a la idea de una "sicaresca" como género. El lenguaje

\footnotetext{
${ }^{1}$ En adelante usaremos la abreviatura LVS.
} 
adquiere para ella un rol fundamental, no obstante la ambigüedad que presenta en el tejido discursivo, (el sujeto) interpela al narratario para que desde la razón haga visible y construya un significado de la violencia exacerbada que presenta el texto. María Helena Rueda intenta mostrar que en la novela se observa la presencia de una ciudad desplazada y los sentidos del desplazamiento, entre los cuales emerge el odio que deriva de una nueva forma de violencia, como sería la del narcotráfico. Por otra parte, a partir del reconocimiento de la propuesta ética de la narrativa de Vallejo, Gabriela Polit propone "mirar al sicario desde la crítica literaria como objeto de violencia", intentando establecer "la manera en que la obra de arte entabla un diálogo con la historia”, lo cual se logra, según ella, a través de un discurso de carácter neo-fascista. La lectura de Elsy Rosas tiende a una visión de LVS como una extensión de la narrativa de transculturación. En el texto se aprecia la intención del narrador por comprender in situ el lenguaje y la subcultura de una comunidad específica de Colombia, ficcionalizando su oralidad; el narrador logra aprender, interpretar y usar la lengua del sicario. César Valencia plantea una lectura simbólica, a partir de la presentación de Medellín como el "infierno sagrado" en que sus ciudadanos están signados por el desarraigo y la soledad. A través de un lenguaje poético, el texto se erige como "un testimonio de la barbarie y el desenfreno de una sociedad enferma". Camila Segura, en una original interpretación, señala que por medio de la diatriba se construye una actitud crítica y desacralizadora donde a su parecer "nada queda intacto", lo cual se logra empleando la "ironía kinica"2 como forma argumentativa que por su manera de ser planteada difícilmente puede contraargumentarse, generando una resistencia al discurso oficial. Aileen El-Kadi apunta en LVS a una gramática del caos, que se puede interpretar como el ordenamiento de la crítica a la percepción de crisis general, puesta de manifiesto desde la discursividad de Fernando y construida a partir de su rol de gramático. Por último, María Mercedes Jaramillo también observa en LVS

${ }^{2}$ Término que adopta siguiendo las ideas de Peter Sloterdijk. 
que para el narrador "nada escapa a su afán desacralizador y a su mirada crítica", con un discurso de tono paródico, irreverente, agresivo, en que el lenguaje se constituye en un elemento provocador, obligando al lector a salir de su pasividad, para que haga emerger y confiera significado "a todas las posibilidades de la violencia y a las miserias humanas" que sacuden a Medellín y a Colombia.

En el ámbito de las tesis doctorales, Jácome Liévano adopta el término "sicaresca" preocupándose por definir y establecer los alcances de este género, siendo LVS la novela emblemática del mismo. Jácome señala que el lenguaje es preponderante en la comprensión de la violencia desatada en Medellín y expresada en el texto, que se logra por la intrusión de la oralidad en la escritura, a través del idiolecto antioqueño (parlache). Para Jácome, Vallejo intenta, por medio de la transformación del lenguaje, cuestionar el discurso de la historia y, a la vez, preguntarse acerca de "las causas, la violencia y la impunidad de los crímenes" que los sicarios cometen.

De los estudios revisados se desprenden a nuestro juicio tres ideas principales en torno a LVS. En primer lugar, la proposición de algunas investigadoras en el sentido de conformar un género a partir del sicario y su contexto, denominado como "sicaresca"; 3 en se-

${ }^{3}$ La formación de género en ese sentido es una idea discutible. Por una parte observamos que von der Walde, en el título de su artículo, ocupa el término "sicaresca"; al año siguiente, en el desarrollo de otro artículo vinculado al tema, hace referencia a un nuevo sub-género literario (28). Por otra parte, la propuesta de Jácome es reductiva . Si bien comprendemos que hay una homologación de orden fónico-conceptual con la picaresca española, que se origina en España, se propaga a otros países de Europa y se extiende a México, no es posible dejar de tomar en cuenta que su espacio se limita a la región de Antioquia y que no todos los requisitos esenciales que configuran al pícaro y a la picaresca se validan en el sicario y la "sicaresca". Lo más importante: el pícaro no es un asesino.

También es necesario considerar que en Colombia y México se emplea el término narconovela, acuñado por la Dra. Chloe Rutter, que tiende a ser más amplio, ya que no sólo se limita a la novela de sicarios, sino que abarca el conjunto de novelas que representan desde distintas perspectivas los diversos elementos que componen y articulan el mundo del tráfico de drogas en Latinoamérica; sin embargo, este término también podría ser susceptible de ser entendido como un sub-género. 
gundo lugar, la importancia que reviste el lenguaje en la representación de la violencia, especialmente en la recreación de la oralidad; y por último, el marcado sentido crítico que atraviesa la novela, que el autor evidencia en el texto a través de una pregunta, motivadora del epígrafe de este artículo. En relación con las dos primeras ideas no pretendemos hacer mayor referencia, estimando que deben ser objeto de estudios separados; sin embargo, en relación con la crítica que se desprende del texto es posible aportar una mirada desde otra perspectiva.

En consecuencia, nuestra propuesta para comprender el sentido crítico del texto la asociamos a la idea de poder, que en el texto se construye desde dos elementos gravitantes: el lenguaje y la historia. Desde el lenguaje, por el empleo de la diatriba, del tono paródico, de la irreverencia, de la ironía, a través de una mixtura entre la lengua oficial que emplea el gramático Fernando y el parlache, producto de sus vinculaciones con los sicarios Alexis y Wílmar, sus sicarios amantes. En ese sentido, desde aquí se articula una visión de la historia y del discurso oficial que desemboca en una crítica furibunda, que en una lectura aparencial puede entenderse como trivial, cínica o marcada por la influencia de la excesiva misoginia del protagonista, pero que en una dimensión más profunda deja una huella kinica, concordando con Segura Bonett, ya que es difícil argumentar contra el tejido de sucesos negativos que ha construido la historia y que ahora ejerce, como consecuencia, su deterioro sobre Medellín y por extensión sobre Colombia. De este modo, debemos entender y considerar a LVS como una novela que instala una problemática, la de la violencia, que es propia de nuestra región y que se asocia a la idea del uso del poder.

En virtud de lo expuesto es posible señalar que la novela está signada por una crítica a los poderes que han formado y regido el estado-nación de Colombia y que con el devenir han ingresado en un proceso de acentuada descomposición, que se hace más visible

Estimamos que es mejor hablar de novelas del narcotráfico, como variante del neopolicíaco, y evitar el aumento de las controversias en torno a la idea de género. 
en la etapa de mayor esplendor de los carteles. En ese sentido, como soporte de nuestra propuesta recurriremos a Michel Foucault, quien sostiene que el poder se debe entender como

La multiplicidad de las relaciones de fuerza inmanentes y propias del dominio en que se ejercen y que son constitutivas de su organización; el juego que por medio de luchas y enfrentamientos incesantes las transforma, las refuerza, las invierte; los apoyos que dichas relaciones de fuerza encuentran las unas en las otras, de modo que forman cadena o sistema, o, lo contrario, los corrimientos, las contradicciones que aíslan a unas de otras; las estrategias, por último que las tornan efectivas, y cuyo dibujo general o cristalización institucional toma forma en los aparatos estatales, en la formulación de la ley, en las hegemonías sociales. (112-113)

El poder, desde esta perspectiva, no debe entenderse como un punto central, único y estático, del cual se derivarían sus directrices y acciones. Por el contrario, el poder puede estar en múltiples lugares, en distintas formas de dominio, con sus propias movilidades y estrategias, que originan un conjunto de relaciones de poder que permiten articularlo. ${ }^{4}$ En consecuencia, el poder no se circunscribe a una oposición de carácter binario entre dominadores y dominados, que se construye desde el dominador, sino que también proviene desde el dominado (las resistencias); cada uno constituye su propio dominio con sus propias relaciones de fuerza, las cuales tienden a multiplicarse en cada uno de estos elementos, dando origen a distintos tipos de dominación que, según Castro, son "las múltiples formas en las que se puede ejercer el poder en una sociedad" (101).

$\mathrm{El}$ poder y sus relaciones en la forma en que es ejercido se constituyen a partir de lo que Foucault llama la microfísica del poder, entendida no como la reducción de elementos visibles, sino como

\footnotetext{
${ }^{4}$ Para una comprensión más cabal de las proposiciones de Foucault en torno a la idea de poder y sus relaciones, véase la esclarecedora exposición que efectúa Deleuze a través de lo que denomina "postulados" (51-56).
} 
otros tipos de dominio, que no comprenden solamente al Estado, sino que generan diferentes tipos de relaciones, con diversas localizaciones; en éstas no se encuentra un poder, sino varios poderes, con distintas características de dominación: "Se trata de formas locales, regionales de poder, que poseen su propia modalidad de funcionamiento, procedimiento y técnica" (Las redes 50).

En LVS es posible observar tres formas de dominio que se pueden demarcar a través de la diégesis: el Estado, la Iglesia y el narcotráfico. Desde estos elementos se elabora la crítica que se gesta en el doble espacio de Medellín, el centro y sus comunas enclavadas en las colinas, y que, a través de una enunciación que emplea un lenguaje que se nutre de un español estándar y del parlache, se puede extrapolar a Colombia, con personajes que se construyen históricamente desde la realidad de esa localidad, en el contexto de sus tradiciones y vivencias.

LVS refleja no sólo la descomposición de poderes, sino también el deterioro y la fragmentación social por medio de un ejercicio crítico a una serie de instituciones que se configuran en la modernidad y que forman parte de la tradición occidental, algunas de las cuales el narrador pone en entredicho y desvirtúa; nos referimos al Estado, el Parlamento, el poder judicial, La Iglesia, la familia, el matrimonio, el presidente de la República.

Los dominios antes señalados tienden a cruzarse en el desarrollo histórico, pero en función de los objetivos de nuestro trabajo los revisaremos separadamente. En primer lugar, en LVS hay que remitirse a lo que podríamos llamar el Estado-nación y la razón histórica. Sin una adecuada comprensión de la formación y desarrollo de la nación resultaría difícil encontrar una explicación de su estado actual.

Colombia ha tenido, desde su independencia, el 20 de julio de 1820, hasta el fin del siglo XIX, varias decenas de guerras civiles, producto de una ardua disputa entre centralistas y federalistas, que no lograron configurar un proyecto estable de nación. Entre 1878 y 1998 aparece el movimiento de la Regeneración encabezado por el presidente Rafael Núñez que promulga una constitución que moderniza el estado y su sistema administrativo, pero que es incapaz 
de brindar derechos y garantías que articulen la paz. En la formación de dicha Carta aparece la figura de Miguel Antonio Caro, un connotado lingüista que va a introducir la figura de los letrados en el campo de la política, quienes junto a los prelados van a ejercer el dominio de la sociedad colombiana, constituyéndose en dos estamentos privilegiados de dicha sociedad. Lengua y religión quedan fuera del ámbito de la discusión política. El gobierno de Caro (1892-98) ayudó a acrecentar las desigualdades sociales. Ilustrativo resulta lo que dice von der Walde:

La ciudad letrada de Caro no discutía ideas: censuraba, sancionaba, prohibía y usaba violencia.

Así se va configurando un lugar de la letra en la cultura: la letra no es el camino para buscar, debatir, cotejar, postular; se erige como un lugar de exclusión. Desde la letra no se piensa al país real sino que se impone el país que conciben unos pocos como país ideal. (2000)

En 1889, en la "guerra de los mil días", fallecen más de cien mil personas. De esta manera se va conformando una espiral de violencia en el país que se sostiene prolongadamente con un Estado ineficaz, con sectores rurales que van a mantenerse en una pobreza degradante, lo cual tendrá una fuerte gravitación en el correr del siglo siguiente.

En el siglo XX, la disputa permanece entre los partidos Conservador y Liberal. Los primeros van a mantener el poder hasta el advenimiento del Liberal Olaya Herrera (1930-34), cuando se producen nuevas convulsiones sociales, que son consideradas como el punto de partida de la violencia que ha llegado hasta nuestros días. En esa época surge la figura de Jorge Eliécer Gaitán como líder Liberal, que dirige la alcaldía de Bogotá desde 1930 y se presenta como candidato presidencial en 1946, siendo derrotado y sus seguidores perseguidos. En 1948 es asesinado, desencadenándose lo que se conoce históricamente como el "bogotazo", que se tradujo en la destrucción del centro de la ciudad, saqueos e incendios y una profunda conmoción en toda la nación. De nuevo aparece la ten- 
sión política en la que se aprecia la profunda división entre la fastuosidad de los que gobiernan y la pobreza de los sectores rurales, que comienzan a sembrar la semilla de lo que en el futuro se va a convertir en una respuesta violenta como expresión de las guerrillas. En ese sentido es relevante lo que señala Areces, quien dice que: "La violencia es un fenómeno esencialmente rural. Constituye una de las mayores movilizaciones armadas de campesinos de la historia de Occidente. Específicamente surge, [...] por la frustración de la revolución social de 1948" (304); y continúa señalando que en el desarrollo del proceso de evolución de las guerrillas se pueden distinguir tres fases:

$1^{\circ}$ La guerrilla de tipo partidista, entre 1948 y 1953. $2^{\circ}$ Como secuela de la anterior, el bandolerismo anárquico. $3^{\circ}$ desde 1963 la que hoy existe, la guerrilla revolucionaria, con fines políticos, inmersa en el contexto de descomposición de las posiciones y de los puntos de apoyo del imperialismo. (304)

Después de 1963 se precipitan varias situaciones, muchas de ellas cruentas, pero hay dos que merecen ser destacadas por su trascendencia. La primera, en 1964, cuando los guerrilleros han establecido la "república independiente de Marquetalia" y son destruidos por dieciséis mil efectivos del Ejército, con asesoría norteamericana. La segunda, en 1985, el asalto e incendio del Palacio de Justicia por parte de las guerrillas del M 19 durante el gobierno de Belisario Betancourt, que consigue poner en tela de juicio toda la estructura del estado colombiano, demostrando la permeabilidad y fragilidad de las instituciones, que pasivamente deben aceptar la concomitancia de ese grupo con el narcotráfico, un tipo de dominio que aparece soterrado para luego emerger y unirse con dichos grupos mediante el financiamiento a sus actividades.

La violencia, como se ha podido observar, se ha mantenido de una manera latente en Colombia a través del tiempo, sin que los ciudadanos permanezcan impasibles ante sus manifestaciones, como es el caso de Fernando, narrador protagonista de LVS, un hombre maduro, que por ser gramático se constituye en el heredero de la 
tradición de cultura y de poder de un determinado sector social, los dominadores, los pudientes, a los cuales él pertenece. Tiene una visión crítica del país y la ejerce, a nuestro juicio, desde dos puntos de vista que quedan claramente expresados en lo siguiente: "Señor Procurador: Yo soy la memoria de Colombia y su conciencia y después de mí no sigue nada" (21); esta visión crítica se respalda, aunque no lo parezca, en un afecto a su país, lo cual hace saber desde la primera página del texto, cuando se refiere a la imagen del Corazón de Jesús que tenía en su antigua casa de Medellín: "A él está consagrada Colombia, mi patria" (7). Nótese que el uso del adjetivo posesivo mi enfatiza la idea de posesión o pertenencia a su propio país, lo cual implica una relación afectiva con lo que ocurre allí. También, Fernando ha sido un espectador cercano y lejano de los sucesos que acaecen en Colombia y ha sentido el paso del tiempo y de la historia, lo cual queda corroborado en el momento en que hace referencia a lo siguiente:

[...] el levantamiento de cadáver, ay, no se realizará más. Una institución tan entrañable, tan colombiana, tan nuestra... Nunca más. El tiempo barre con todo y las costumbres. Así, de cambio en cambio, paso a paso, van perdiendo las sociedades la cohesión, la identidad, y quedan hechas unas colchas deshilachadas de retazos. (30)

La visión pesimista se ahonda mientras recorre Medellín en compañía de su sicario amante, conociendo gente, descubriendo nuevas actitudes en las personas y reconociendo lugares, que lo hacen percibir un Medellín en el que está todo torcido y en el que el Estado adquiere la mayor responsabilidad en este deterioro. Su malestar lo hace saber:

Apuntalado en una precaria legitimidad electorera, presidido por un bobo marica, fabricador de armas y destilador de aguardiente, forjador de constituciones impunes, lavador de dólares, aprovechador de la coca, atracador de impuestos, el Estado de Colombia es el primer delincuente. Y no hay forma 
de acabarlo. Es un cáncer que nos va royendo, matando de a poquito. (84)

Lo expresado por Fernando se complementa con una visión que pone en tela de juicio a la ley y al presidente de la nación; él no trepida en su crítica cuando dice que: "La ley de Colombia es la impunidad y nuestro primer delincuente impune es el presidente" (20). De ser así, sólo cabe entender que en el orden social todo hacia abajo será desorden.

En segundo lugar, aparece comprometido el dominio de la Iglesia con su vasta tradición e influencia histórica en la formación de la nación. La raíz católica marca su presencia amparando un proyecto civilizador y propagándose a aquellos que detentan el poder a través de la instrucción. El resto del pueblo quedó fuera de esta posibilidad. La situación llega a tal punto que el gobierno de Caro va a definir qué es ser católico y, por otra parte, la fe católica se va a cobijar en el más rancio conservadurismo, cuyo partido político se va a sostener durante más de cuatro décadas (1886-1930) en el poder.

En la Iglesia de Colombia se van a producir algunas modificaciones sustanciales en la década de los sesenta, cuando surgen voces disidentes que ven con dolor cómo aquélla no está junto a los más necesitados. Desde el seno de este dominio se hace notar la presencia del sacerdote Camilo Torres, que comienza a estudiar y escribir sobre distintos aspectos de la realidad colombiana. Su visión de la sociedad le genera fuertes contradicciones que lo llevan a fines de 1965 a dejar su vocación religiosa y a enrolarse y dirigir el ELN (Ejército de Liberación Nacional), donde dejará su vida en una emboscada que le tiende el ejército. La explicación de Torres es reveladora de acuerdo al texto que cita Alberto J. Pla:

Yo he dejado los deberes y privilegios del clero, pero no he dejado de ser sacerdote. Creo que me he entregado a la revolución por amor al prójimo. He dejado de decir misa para realizar ese amor al prójimo en el terreno temporal, económico y social. Cuando mi prójimo no tenga nada contra mí. Cuan- 
do haya realizado la revolución, volveré a ofrecer misa si Dios me lo permite. (514)

Para la Iglesia corren tiempos de tensión, ya que es fuertemente cuestionada en relación con su comportamiento histórico, en vatios aspectos tales como su falta de atención hacia las masas campesinas y marginales, su marcada solidaridad con los grupos dominantes, su incapacidad de organización, su sentido colonialista, la mala administración de los bienes eclesiásticos, la enseñanza clasista y el tipo de religión que se enseña (Cavallioti 129-130).

La respuesta va a provenir del CELAM (Conferencia Episcopal Latinoamericana) en su Segunda Conferencia General de Medellín, en 1968, en la que se instala por primera vez la palabra "liberación”, según lo señalado por Cavalliotti: "Pónganse de pie y levanten la cabeza, porque está por llegarles la liberación” (125). Surge la llamada Teología de la Liberación, que a nivel de prelados coloca a la Iglesia cerca de los pobres y oprimidos. ${ }^{5}$ Desde esa fecha en adelante las cartas episcopales van a reflejar una postura distinta de la Iglesia, con un mayor énfasis en lo social y más cercana al desprotegido.

Fernando ha sido criado bajo el amparo de la tradición religiosa, pero su visión de lo que se presenta ante su mirada y su conciencia hace que, luego de vivir muchos años fuera del país, su actitud sea de crítica y cuestionamiento por el sentido y forma de manifestación de la religiosidad. Le cuesta entender los cambios que observa en el ámbito religioso y se resiste a aceptarlos:

Ha de saber Dios que todo lo ve, lo oye y lo entiende, que en su Basílica Mayor, nuestra Catedral Metropolitana, en las bancas de atrás se venden los muchachos y los travestis, se comercia en armas y en drogas y se fuma marihuana. Por eso,

${ }^{5}$ Junto al sacerdote Torres, en la misma época, surge la importante figura del obispo de Pernambuco Helder Cámara, quien también alza su voz de rebelión, pero con diferentes métodos. Su elección es la no violencia y cambiar desde dentro la imagen de la Iglesia. 
cuando está abierta suele haber un policía vigilando. Pregúntenle a ver si invento. ¿Y Cristo dónde está? (53)

Fernando ve un mundo trastocado, con valores tergiversados, con una motivación religiosa que no guarda relación con la forma de hacer religión cuando él dejó el país y el momento en que la posmodernidad muestra sus rasgos. Ahora Dios desdobla su rol y concede su "bendición" a aquel que va a matar en el momento que ofrenda sus balas y le pide que lleguen a buen destino: el cuerpo humano y sin dolor. Por otra parte, el escapulario adquiere una valoración diferente: “...con tres escapularios, que son los que llevan los sicarios: uno en el cuello, otro en el antebrazo, otro en el tobillo y son: para que les den el negocio, para que no les falle la puntería y para que les paguen" (16).

Y si el signo de la corrupción ha caracterizado a los políticos en Colombia, también va a penetrar a la curia, que no va a vacilar en el momento que deba hacer negocios con el narcotráfico, transgrediendo la ética y la moral cristiana, lo cual se refleja cuando se refiere el narrador al Cardenal López T.:

Muy delicadito él, de modales finos y adamados, perfumado, se empeñó en hacer negocio con el narcotráfico, el único que tenía dinero constante y sonante. Cartas quedan de este Cardenal al gran capo ofreciéndole en venta terrenos de la curia. ¿Y no le importaban al Cardenal -preguntará usted- los incontables muertos de las bombas, de las muchas que mandó estallar el gran capo, todos ellos gentecitas humildes y buenas, del "pueblo"? (69)

Un sector de la Iglesia colombiana es atravesado por los síntomas de la crisis, no obstante los ingentes esfuerzos que hace para contribuir a la pacificación del país y a la estabilización de sus instituciones. Resulta evidente que los dominios del Estado y de la Iglesia no tienen la capacidad para contrarrestar el desquicio social y la moral degradada, que tiene sus orígenes en una violencia fuera de todo control. Se vive el caos, lo cual se refleja en la siguiente visión de Fernando: 
Nada funciona aquí. Ni la ley del talión ni la ley de Cristo. La primera, porque el Estado no la aplica ni la deja aplicar: ni raja ni presta el hacha como mi difunta mamá. La segunda, porque es intrínsicamente perversa. Cristo es el gran introductor de la impunidad y el desorden de este mundo. Cuando tú vuelves en Colombia la otra mejilla, de un segundo trancazo te acaban de desprender la retina. Y una vez que no ves, te cascan de una puñalada en el corazón. (73)

En tercer lugar, el narcotráfico aparece de manera incipiente para desarrollarse posteriormente como una fuerza devastadora, provisto de un gran caudal de capital generado desde la ilegalidad de sus negocios tanto dentro del país como en el exterior; un país que “...está lleno de muertos. Cuando Alexis llegó a los cien definitivamente perdí la cuenta" (76), nos dice Fernando reflejando de un modo brutal el nuevo orden que rige este dominio y su forma de ejercerlo.

El narcotráfico ingresa en la escena colombiana en la década de los setenta hasta llegar a un punto de gran auge alrededor de 1985, cuando prácticamente tenía el control de la ciudad de Medellín. La elaboración de pasta básica y cocaína constituye su mayor producción de droga. Es un dominio que para sostenerse e instituirse tiene sus componentes naturales en el crimen organizado, la violencia y la corrupción. Sus tentáculos crecen de tal manera que no le es difícil penetrar las estructuras de la sociedad civil, corrompiendo a jueces, políticos, policías o funcionarios de gobierno. El volumen del negocio es tan alto que le permite generar empleos directos e indirectos como tabla de salvación para los sectores más desposeídos y ganarse su favor. Además ese sector es asistido por el narcotráfico con bienes y servicios, tales como colocar alcantarillado en una población o pagarles cuentas de electricidad, entre otros, como ocurre con el cártel de Medellín dirigido por Pablo Escobar, quien tiene gran raigambre popular y que es considerado un bienhechor por los desposeídos, y cuya muerte en 1993, junto con ser un duro golpe al poder de los narcos, también provoca un dolor a esa gente, que presiente que la situación va a cambiar, que no habrá 
más empleo. El oficio de sicario se viene a menos, tal como lo dice Fernando:

Con la muerte del presunto narcotraficante que dijo arriba nuestro primer mandatario, aquí prácticamente la profesión de sicario se acabó. Muerto el santo se acabó el milagro. Sin trabajo fijo, se dispersaron por la ciudad y se pusieron a secuestrar, a robar. Y sicario que trabaja solo por su cuenta y riesgo ya no es sicario: es libre empresa, la iniciativa privada. (34)

El sicario es un muchacho de corta edad, iletrado, que nace en medio de la violencia y estima que ésta es el cauce natural para resolver sus conflictos y satisfacer sus necesidades. Se forma en las bandas juveniles de las comunas, que se encuentran enclavadas en las laderas de las colinas de Medellín. En 1990 había más de tres mil jóvenes incorporados a ciento veinte bandas aproximadamente. En las comunas se vive en condiciones de hacinamiento, es decir con alta densidad demográfica, viviendas de mala calidad y con servicios públicos mínimos. Las opciones de progreso no existen, y para los jóvenes, según Salazar,

El narcotráfico se convirtió en una opción para amplios sectores de la población, que encontraron una alternativa de promoción social y económica. Posteriormente la mafia se convirtió en modelo de referencia para la juventud, que vio la forma de realizar sus deseos de estatus y bienestar que las opciones tradicionales de estudio y trabajo les negaban. Las bandas juveniles propias de cualquier ciudad se relacionaron, o fueron influenciadas, por los cárteles y este hecho les dio una connotación especial. (152)

No deja de ser significativo que cuando Fernando, a pocas horas de conocer a Wílmar, quien después se transformará en su amante, mientras almuerza le dice que anote en una servilleta lo que espera de la vida y recibe como respuesta una lista de diversos artículos y prendas de buena marca. Para el sicario la forma de lograr aquello 
no radica en el esfuerzo, sino en el acto delictivo que le reporte rápidamente el dinero fácil, para gastarlo y disfrutarlo de inmediato, en el marco de un falso estatus. ${ }^{6}$ Su expectativa de vida en ese contexto es corta y él lo sabe.

En relación con este dominio es necesario revisar la génesis de la formación social del sicario, que se debe vincular a la época de la denominada Violencia, que asoló a Colombia entre 1945 y 1965. A este respecto Osorio dice:

El balance de la Violencia es dramático: más de 200.000 muertos, extensos cinturones de miserias en las ciudades por cuenta del desplazamiento forzoso. El tejido social descompuesto, enriquecimiento y acumulación de capitales de la oligarquía, empobrecimiento extremo y pauperización de las clases populares. (97)

Los campesinos escapan de los sectores rurales y se ubican en las periferias de las ciudades, tal es el caso de Medellín, que ve incrementada su población como consecuencia del surgimiento de las modernas guerrillas, que van a reemplazar a las antiguas bandas, y después con las aparición del narcotráfico se va a acentuar este proceso de desplazamiento forzoso, ${ }^{7}$ que coloca a Colombia entre los dos mayores países del mundo en esta materia. Los campesinos cambian de lugar, pero en ningún caso sus condiciones de vida; continúan igual, llevan el germen de la violencia y arrastran el dolor y la amargura de su pobreza. Ellos son, como lo señala Fernando, los fundadores:

${ }^{6}$ Un ejemplo de esta situación lo constituye Capeto, el personaje central de la novela Hijos de la nieve de José Libardo Porras, quien entra en el negocio de la droga, con el cual obtiene ingentes cantidades de dinero que le permite cambiar su condición de vida y salir junto a su familia del barrio humilde para trasladarse a un sector de gente pudiente, donde no es bien visto. Al final pierde el negocio, cae preso y los suyos vuelven al mismo origen.

${ }^{7}$ Las cifras que entrega el Boletín N ${ }^{0} 69$ de septiembre de 2006 de la Consultoría para los Derechos Humanos y el Desplazamiento, Codhes, con sede en Bogotá, no 
Los fundadores, ya se sabe, eran campesinos: gentecita humilde que traía del campo sus costumbres, como rezar el rosario, beber aguardiente, robarle al vecino y matarse por chichiguas con el prójimo en peleas a machete. ¿Qué podía nacer de semejante esplendor humano? Más. Y más y más y más. Y matándose por chichiguas siguieron: después el machete a cuchillo y después del cuchillo a bala, y en bala están hoy cuando escribo. (29)

Por último, hay un dominio, el de las guerrillas, que no adquiere relevancia en el texto y por esta razón hemos decidido no abordarlo en el presente estudio; sin embargo, no es posible soslayar su concomitancia con el narcotráfico. Tanto los grupos guerrilleros de izquierda FARC, ELN, como los de derecha a través de las AUC o paramilitares, mantiene vínculos con sectores del narcotráfico, ya sea para proteger zonas de cultivo de coca, su procesamiento en laboratorios clandestinos o los largos desplazamientos de toneladas de cargamentos a los lugares de distribución o puntos de embarque hacia el extranjero, especialmente México, cuya frontera norte es la puerta de entrada de las drogas a Estados Unidos. La ayuda entre los narcotraficantes y los grupos guerrilleros es mutua ya que ambos se necesitan en función de sus particulares objetivos.

A través del narrador-protagonista es posible observar el proceso de descomposición en que ha derivado el país, situación que también se aprecia en él. Por una parte, su virulento discurso con-

deja de ser alarmante porque sus cifras abren un debate político que nuevamente pone al Estado en juicio. Por una parte el gobierno señala que entre el $1^{\circ}$ de enero de 1995 y el 30 de junio de 2005, un total de 1.877 .328 personas desplazadas se encuentran inscritas en el Sistema Único de Registro (SUR). Lo significativo es que el 43.2\% (812.178) corresponde al primer mandato del reelegido presidente Uribe. Las cifras de Codhes indican que entre el $1^{\circ}$ de enero de 1985 y el 30 de junio de 2006, 3.832.527 personas se han desplazado, lo cual parece indicar, tal como lo expresa el organismo consultor, que es imprescindible el diseño a nivel gubernamental de una política seria y sostenible. 
tra la iglesia: "Y yo pensando que la Iglesia andaba en más bancarrota que el comunismo... Qué va, está viva, respira. La humanidad necesita para vivir mitos y mentiras" (15), y por otra, contradictoriamente, en la misma secuencia narrativa su fervoroso rezo:

Virgencita niña, María Auxiliadora que te conozco desde mi infancia, desde el colegio de los salesianos donde estudié; que eres más mía que de esta multitud novelera, hazme un favor: Que este niño que ves rezándote, ante ti, a mi lado, que sea mi último y definitivo amor; que no lo traicione, que no me traicione, amén. (15)

Fernando acentúa su proceso de contradicciones en la medida que desarrolla sus relaciones con sus dos amantes sicarios. Si bien vive de los recuerdos, pensando en sus años de adolescencia en Medellín, por otra parte, comienza a insertarse en el nuevo estilo de vida que se impone sobre la ciudad signado por la violencia, a la cual él termina incorporándose de manera activa desde dos formas: primero, conociendo la jerga de los sicarios e incorporándola a su lenguaje, situación curiosa para un gramático; segundo, participando de los asesinatos y convirtiéndose en cómplice, como ocurre en el caso del transeúnte que tropieza con Fernando y Alexis y les dice: "Aprendan a caminar maricas"; el transeúnte recibe como respuesta una bala en la boca, disparada por Alexis, acto que Fernando termina inexplicablemente por justificar:

Sí, niño, esta vez sí me parece bien lo que hiciste, aunque de malgenio en malgenio, de grosero en grosero vamos acabando con Medellín. Hay que desocupar a Antioquia de antioqueños malos y repoblarla de antioqueños buenos, así sea este un contrasentido ontológico. (42)

Fernando ha llegado a Medellín a vivir sus últimos años de vida erigiéndose, tal como él lo señala, en memoria y conciencia sobre las cuales efectúa un ejercicio crítico acerca de la ciudad y el país; sin embargo, ha terminado por homologarse con la violencia y la crisis que vive esa región, lo cual podría restar dimensión moral a 
dicha crítica, pero en ningún caso la despoja de su sentido de profunda verdad.

En conclusión, es posible señalar dos ideas centrales. En primer lugar, que $L V S$ es una novela que establece un ejercicio crítico acerca de la sociedad colombiana finisecular construido desde un particular lenguaje y en un estilo marcado por la irreverencia y la ironía; dicha crítica se construye sobre un trasfondo histórico en el cual se pueden percibir las causas y el desarrollo de determinados dominios con sus correspondientes estrategias de poder que han contribuido a cimentar un proceso de violencia creciente, casi inevitable y que con la emergencia del narcotráfico aumentó considerablemente hasta hacerse insostenible a finales de la década de los ochenta.

En segundo lugar, como consecuencia de lo anterior, las diversas instituciones que configuran el Estado-nación entraron en un estado de descomposición del que da cuenta el discurso de LVS; en esta novela el factor corrupción adquiere ribetes insospechados y un rol preponderante en la falta de credibilidad en dichas instituciones, que no han podido corregir, no obstante algunos signos estadísticos que hablan de una baja de las tasas de homicidio y delincuencia durante el mandato del presidente Uribe y una posición más dura de ese gobierno ante el narcotráfico y las guerrillas. Sin embargo, hay una serie de hechos que son síntomas preocupantes. Por ejemplo, los dos grandes cárteles, Cali y Medellín, cayeron, pero en su reemplazo aparecen más de doscientos "cartelitos" con estructuras altamente compartimentadas que continúan con el negocio de las drogas, el cual sigue siendo de alta rentabilidad y mantiene su mismo nivel de producción, incluso provocando la expansión del mismo en México con los resultados que se aprecian: incremento del tráfico de drogas en ese país, expansión territorial de los cárteles y aumento de su violencia, al punto que el gobierno entrante de Calderón, a principio de 2007, saca a más de sesenta mil efectivos del ejército a la calle ante el desborde de la situación. Por otra parte, la cifra de desplazados en Colombia va en constante crecimiento, sin señales de correcciones. Se mantienen los secuestros y la seguridad no está garantizada ni para los miembros de las más altas esferas, como ocurre con los once ex diputados regionales se- 
cuestrados en el año 2002 y asesinados en junio de 2007. Situaciones que hablan de un contrasentido entre las decisiones y las acciones del Estado.

LVS, desde un lenguaje y estilo particulares, genera una crítica enfocada a los sectores que detentan el poder en la sociedad colombiana, pero en un sentido proyectivo; tal crítica parece seguir validándose en la actualidad en algunos aspectos, en particular en aquello concerniente a la débil capacidad de administración y operatividad del Estado para enfrentar el fenómeno, mal endémico de la nación.

\section{Bibliografía}

Areces, Nidia. "Gaitán. El bogotazo." Historia de América en el siglo XX. Buenos Aires: Centro Editor de América Latina, 1972. Castro, Edgardo. El vocabulario de Michel Foucault. Buenos Aires: Universidad Nacional de Quilmes, 2005.

Cavilliotti, Martha. "Helder Cámara. La crisis en la Iglesia en América Latina." Historia de América en el siglo XX. Buenos Aires: Centro Editor de América Latina, 1972. 129-130.

Deleuze, Gilles. Foucault. Buenos Aires: Paidós, 2005.

El-Kadi, Aileen. "La virgen de los sicarios y una gramática del caos."

Espéculo 35.27 (2007). 27 agosto 2007. <www.ucm.es/info/especulo/numero35/vsicario.html>

Foucault, Michel. Historia de la sexualidad I. La voluntad de saber.

Buenos Aires: Siglo XXI Editores, 2005. . Las redes del poder. Buenos Aires: Lectour, 2005.

Jácome Liévano, Margarita Rosa. "La novela sicaresca: exploraciones ficcionales de la criminalidad juvenil del narcotráfico." Tesis doctoral. University of Iowa. 2006.

Jaramillo, María Mercedes. "Fernando Vallejo: desacralización y memoria." Literatura cultura. Narrativa colombiana del siglo XX. Vol. 2. Eds. María Mercedes Jaramillo, Betty Osorio y Ángela Inés Robledo. Santa Fe de Bogotá: Biblioteca Virtual del Banco de la República, 2004. 407-439. 
Lander, María Fernanda. 'La voz impenitente de la 'sicaresca' colombiana." Revista Iberoamericana 73.218-219 (2007): 287-300.

Osorio, Óscar. Violencia y marginalidad en la literatura latinoamericana. Cali: Editorial Universidad del Valle, 2005.

Pla, Alberto J. "Proclamas y documentos II." Historia de América en el siglo XX. Buenos Aires: Centro Editor de América Latina, 1972. 514.

Polit Dueñas, Gabriela. "Sicarios, delirantes y los efectos del narcotráfico en la literatura colombiana." Hispanic Review 74/2 (Spring 2006): 119-142.

Rosas Crespo, Elsy. "La virgen de los sicarios como extensión de la narrativa de la transculturación." Espéculo 24 (2004). 25 septiembre 2004. <http://www.ucm.es/info/especulo/numero24/ virgen.html>

Rueda, María Helena. "Escrituras del desplazamiento. Los sentidos del desarraigo en la narrativa colombiana reciente." Revista Iberoamericana LXX.207 (2004): 391-408.

Salazar, Alonso. No nacimos pa' semilla. Bogotá: Planeta, 2004.

Segura Bonett, Camila. "Kinismo y melodrama en La virgen de los sicarios y Rosario Tijeras." Estudios de Literatura Colombiana 14 (2004): 111-136.

Valencia Solanilla, César. "La virgen de los sicarios: El sagrado infierno de Fernando Vallejo." Revista de Ciencias Humanas 26 (2004). 02 octubre 2004. < http://www.utp.edu.co/ chumanas/revis$\mathrm{tas} / \mathrm{revistas} / \mathrm{rev} 26 /$ valencia.htm $>$

Vallejo, Fernando. La virgen de los sicarios. Bogotá: Alfaguara, 1998. Von der Walde, Erna. "La sicaresca colombiana. Narrar la violencia en América Latina.” Nueva Sociedad 170 (2000): 222-227. . "La novela de sicarios y la violencia en Colombia." Revista Iberoamericana I.3 (2001): 27-40.

. "Lengua y poder: el proyecto de nación en Colombia a finales del siglo XIX.” Estudios de Lingüistica Española 16 (2002). 25 julio 2007. <http://www.elies.rediris.es/elies16/index.html> 